\title{
The Influence and The Analysis Of Alkyl Ketene Dimers (AKD) to Paper Resistance in Water Absorption and Chemical Solution Penetration
}

\author{
Henny Rochaeni, Candra Irawan, Mira Nurfitriani \\ Jamaludin, Poppy Sri Lestari ${ }^{1}$ \\ Department of Analytical Chemistry \\ Politeknik AKA Bogor \\ Bogor, Indonesia \\ ${ }^{1}$ poppy.srilestari@gmail.com
}

\author{
Unang Rosdiana \\ PT. Pindo Deli Paper Products 2 \\ Karawang, Indonesia
}

\begin{abstract}
Alkyl Ketene Dimers (AKD) is one of the additive chemicals in the paper industry which is used as a sizing agent which functions to improve the hydrophobic properties of paper. The amount of addition of AKD would have an effect on paper durability in water absorption and liquid penetration, so that it needs to be tested. The testing was carried out in four stages, namely the furnish manufacturing stage, the paper-making stage (the hand sheet process), and the cobb size and size effect testing phase. Cobb size and size effect testing was done on paper with a gram size of $\pm 70 \mathrm{~g} / \mathrm{m}^{2}$ with the addition of AKD which varies $(0$, $10,12,14) \mathrm{kg} / \mathrm{T}$. The smaller cobb size value and the larger size effect value was shown every time the AKD was increased. This showed that the more AKD added, the less paper absorbs water and the longer the penetration time of the chemical solution penetrates the paper.
\end{abstract}

Keywords-Alkyl Ketene Dimers; paper durability; water absorption; penetration

\section{INTRODUCTION}

Paper consists of cellulose fibers with a very high-water absorption rate. However, paper used for writing and printing must be resistant to several levels of wetting by liquids such as water, solution and suspension. Therefore, the papermaking component such as fiber is made partially hydropobic by incorporating additive chemicals in paper pulp. This phenomenon is known as sizing [1]. Sizing efficiency of paper is highly dependent upon retention of the sizing agent on papermaking components $[2,3,4,5,6]$.

Alkyl Ketene Dimer (AKD) has been most widely used as a reaction sizing agent in the production of high-quality printing paper. According to [7], one of the most important features of printed paper is the nature of water absorption and ink penetration that affects the perfection of ink absorption and the level of ink retention in sheets. AKD will naturally only work covering a limited area determined by emulsion particles or added droplets [8]. AKD reacts with hydroxyl groups on cellulose fibers and forms a $\beta$-keto ester bond, thus making the paper hydrophobic [9]. The formation of a $\beta$-keto ester between AKD and cellulose hydroxyl groups is proposed to be the primary mechanism for AKD sizing $[10,11]$

\section{EXPERIMENTAL}

\section{A. Material and Tools}

Material for making paper is Leave Bleach Kraft Pulp (LBKP), Needle Bleach Kraft Pulp (NBKP), filler, cationic starch, Optical Brightening Agent (OBA), anionic retention aid, cationic retention aid, Alkyl Ketene Dimers (AKD), water, $1 \%$ solution, and $2 \%$ solution. The tools used are handsheet former, cobb tester, glass container, and plastic pipette.

\section{B. Procedures}

The first stage in making paper is furnishing with the addition of $\operatorname{AKD}(0,10,12,14) \mathrm{kg} / \mathrm{T}$ by mixing ingredients such as LBKP, NBKP, filler, cationic starch, Optical Brightening Agent (OBA), anionic retention aid, cationic retention aid, Alkyl Ketene Dimers (AKD), and water according to the amount calculated on the formula. The formed furnishing is then made into sheets of paper using the hand sheet former tool. The sheets that have been made and were still attached to the blotting paper were stacked and squeezed with a metal plate, then press using a press. Two pressings were carried out until the sheet of paper from the dry hand sheet was then removed from the blotting paper and placed on an iron plate and then stored in a speed dryer. Let stand for 20 minutes and be lifted.

\section{1) Gramatur Testing}

Grammar testing referring to ISO 536 - 2012 was done by measuring the surface area and weighing paper sheets using an analytical balance sheet.

\section{2) Testing the amount of water absorbed by Cobb Size} Paper sample was weighed then a completely dry metal rings was placed on top of the sample and tighten. Then pour 100 $\mathrm{mL}$ of aquadest in a measuring cup quickly into the ring. The top watch was turned on at the same time when the aquadest 
was poured into the ring. After 45 seconds, the water in the ring was poured quickly and the aquadest was avoided dripping into the sample in the outer ring. The metal ring was lifted quickly and the sample was placed between the stack of blotting paper with the test section facing up. The metal roller was moved on top of the stack blotting paper once to the front and once to the rear without any additional pressure. The samples raised were then weighed and the results were recorded. The cobb size value was calculated by the following equation (1),

Cobb Size $\mathrm{g} / \mathrm{m}^{2}=($ Final Weight - Initial Weight $) \mathrm{g} \times 100 \mathrm{~m}^{-2}$

3) Testing the penetration time of liquid How to Size Effect A good, clean, and unwrinkled paper sheet was selected then folded or shaped like a boat (so that it can accommodate the liquid to be dripped on the surface of the paper). After that, put it in a glass container containing $\mathrm{NH}_{4} \mathrm{SCN}$ (2\%), high of solution $\pm 10 \mathrm{~mm}$ then dripped indicator solution of $\mathrm{FeCl}_{3} \cdot 6 \mathrm{H}_{2} \mathrm{O}(1 \%)$. The time of the appearance of a third red spot on the paper surface was measured. Size effect testing was done three times. The value obtained was the result of the average test value

\section{RESULT AND DISCUSSION}

Paper sheets made from furnishing with AKD vary from 0 , 10,12 and $14 \mathrm{~kg} / \mathrm{T}$. The result was paper with a $\pm 70 \mathrm{~g} / \mathrm{m}^{2}$ gramatur, then the cobb size and size effect were tested.

\section{A. Cobb Size Testing}

The cobb size value was the amount of water in grams absorbed by a square meter of sheet of paper. The cobb size value is one indicator for paper durability in water absorption in a certain time. The results of cobb size (direct top and direct bottom) testing experience a decrease in value every time the addition of AKD was increased. AKD added to the papermaking process would react with the cellulose molecule to form a $\beta$-keto ester bond. The proposed mechanism of AKD sizing is the formation of $\beta$-keto ester between AKD and free $\mathrm{OH}$ groups on cellulosic fibers. Ring opening always occurs at the acyloxygen bond (Fig 1) [12,13], so as to improve the hydrophobic nature of the paper which was related to the level of water absorption and fluid penetration [14].

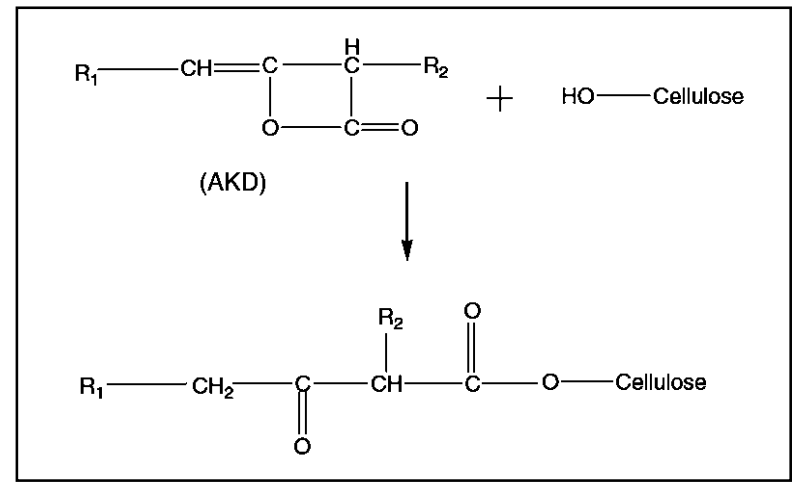

Fig 1. The AKD bond with Cellulose forms $\beta$-ketoester
When the paper did not add AKD $(0 \mathrm{~kg} / \mathrm{T})$, the paper would absorb large amounts of water and make the paper look very wet compared to the paper added by AKD. The more AKD addition, the longer it took for water to pass through AKD particles which were bound to the fiber to the wet surface of the fiber. As a result the less weight of water in one square meter of paper. Automatically the cobb size value got smaller. In addition, there was a difference in values between the results of cobb size direct top test and cobb size direct bottom. This was because the paper surface of the direct top was rougher than direct bottom. Surface roughness would increase the surface area of the hydrophobic material, and its effect could increase hydrophobicity. So that the cobb value of the direct top size was smaller than the cobb size direct bottom. The results of the appearance of water absorption on paper with the addition of AKD can be seen in Fig 2, while the effect of adding AKD to the value of cobb size (direct top and direct bottom) is shown in Fig 3.

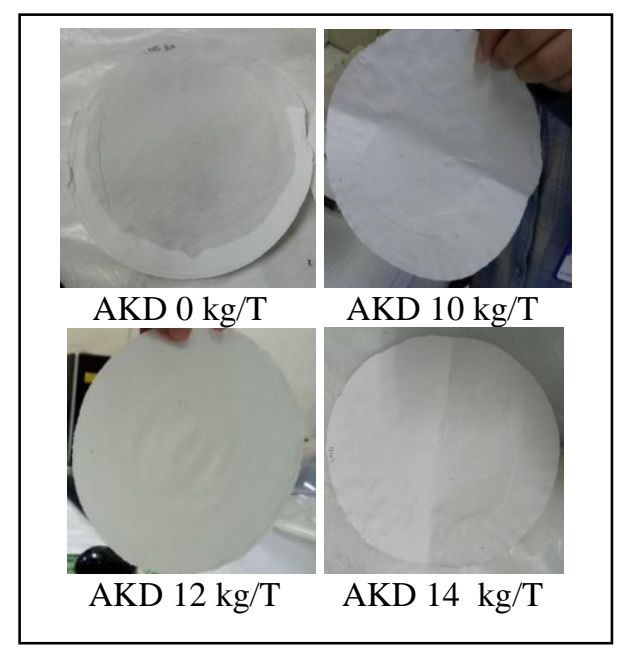

Fig 2. Results of Appearance of Water Absorption on Paper with Addition of AKD

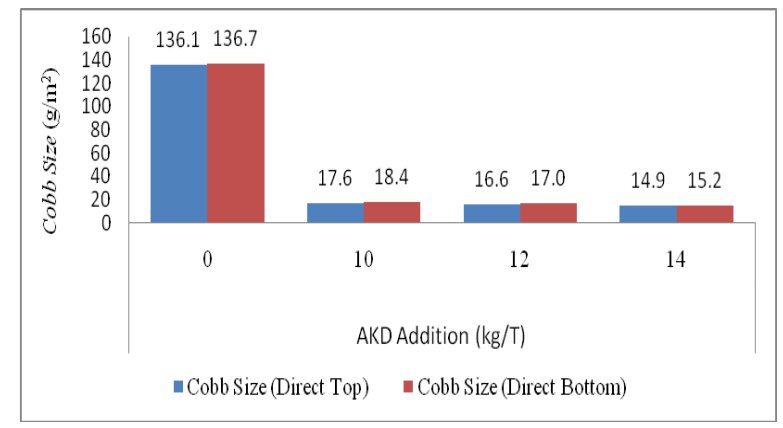

Fig 3. Relation of AKD Addition to Cobb Size Value

\section{B. Size Effect Test}

The penetration time of a chemical through the paper or the durability of the paper in liquid penetration could be indicated by the size effect value produced. The value of the size effect was indicated by the unit of time (seconds). In this case the 
paper would be tested by adding chemical solutions in the form of $\mathrm{NH}_{4} \mathrm{SCN} 2 \%$ and $\mathrm{FeCl}_{3} \cdot 6 \mathrm{H}_{2} \mathrm{O} 1 \%$ from the top and bottom of the paper surface. The paper would get pressure from the bottom or the top that the results would be marked by the appearance of red spots as a result of the reaction of the meeting between the two chemicals. The time of the appearance of these three red spots indicates the durability of the paper in the penetration of the liquid.

The results of size effect test increase in value for each additional AKD. Just like the cobb size test, when the paper was not added AKD $(0 \mathrm{~kg} / \mathrm{T})$ the paper would be penetrated directly by the liquid compared to the paper added by AKD. A high size effect value indicated that the penetration time of a chemical penetrates the paper or paper resistance to liquid penetration was longer. AKD naturally only work in a limited area which was determined by the number of emulsion particles or droplets added [15]. This has been proven by the results of the tests found that the more AKD added would have an effect on paper durability in getting better fluid penetration. The results of the appearance of the penetration power of chemicals on paper with the addition of AKD could be seen in Fig 4, while the effect of adding AKD to the size effect value is shown in Fig 5.

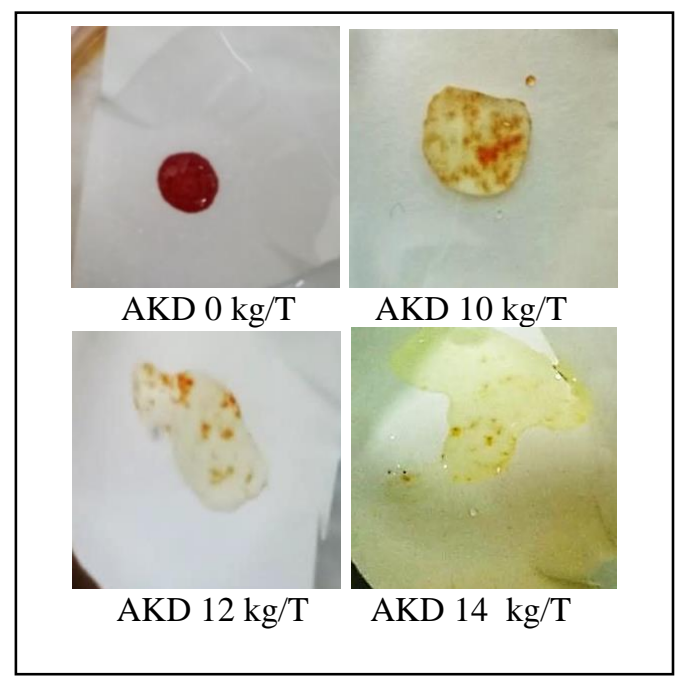

Fig 4. Results of Chemical Penetration Appearance on Paper with Addition of AKD

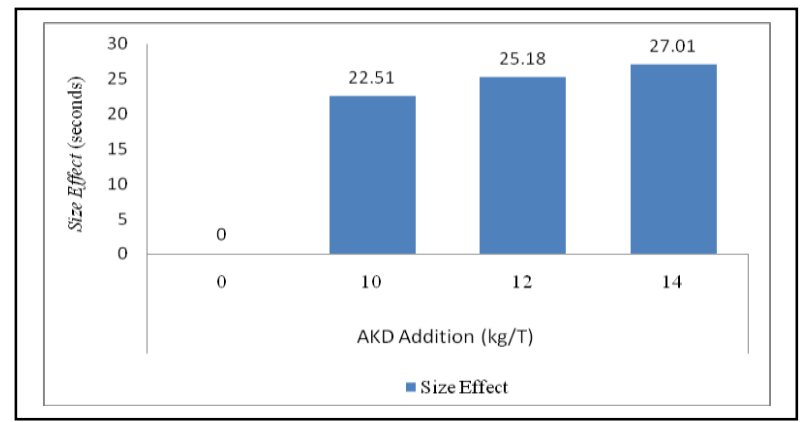

Fig 5. Relationship of Addition of AKD to Size Effect Value

\section{CONCLUSION}

The smaller cobb size value and the larger size effect value was shown every time the AKD was increased. This showed that the more AKD added, the less paper absorbs water and the longer the penetration time of the chemical solution penetrates the paper.

\section{ACKNOWLEDGMENT}

The authors acknowledge the kindness and co-operation of the informants and local administrators in the study area, and the support of the Politeknik AKA Bogor and PT Pindo Deli Paper Products 2.

\section{REFERENCES}

[1] D.B. Evans, The Sizing of Paper, 2nd ed. Tappi Press. 1989.

[2] T. Lindstrom, and G. Soderberg,1986. "On the mechanism of sizing with alkylketene dimers. part 3. the role of ph, electrolytes, retention aids, extractives, ca-lignosulphonates and mode of addition on alkylketene dimer retention, Nord. Pulp Pap. Res. J., VOL. 1(2), pp. 31, 1986

[3] A. Isogai, "Effect of cationic polymer addition on retention of alkylketene dimer, J. Pulp Paper Sci., 23(6), 276, 1997.

[4] S. Champ, and R. Ettl, R.. The Dynamics of Alkylketene Dimer (AKD) Retention, J. Pulp Paper Sci. 30(12), 322, 2004.

[5] J. Johansson, and T. Lindstrom, "A study on AKD-size retention, reaction and sizing efficiency part 1: the effect of pulp bleaching on AKD-sizing, Nord. Pulp Pap. Res. J., vol. 19(3), pp. 330, 2004.

[6] D. Ravnjak, I. Plazl, and A. Moze, "Kinetics of colloidal alkylketene dimer particle deposition on pulp fibers", Colloid Polym. Sci., vol. 285, pp. 907,2007

[7] C.E. Brandon, Properties of paper. pulp and paper chemistry and chemical technology (vol 3). Third Edition. A Wiley - Interscience Publication, New York, 1981.

[8] D. Ravnjak, I. Plazl, and A. Moze. Kinetics of colloidal alkyl ketene dimer particle deposition on pulp fibers, Colloid Polym, 2007.

[9] S. Kumar, S. Vipul, S.K. Chauhan, and Chakrabarti, "Separation and analysis techniques for bound and unbound alkyl ketene dimer (AKD) in paper: A review". Arabian Journal of Chem., vol 9: pp. 1636-1642, 2016.

[10] J.W. Davis, W.H. Robertson, and C.A. Weisgerger, A new sizing agent for paper - alkyl ketene dimmers, Tappi J., vol. 39(1), pp. 21, 1965.

[11] J.C. Roberts, and D.N. Garner, The mechanism of alkyl ketene dimer sizing of paper. part 1, Tappi J., vol. 68(4), pp. 118, 1985.

[12] T.S. Lindstrom, G. Oderberg, "On the mechanism of sizing with " alkylketene dimers. part 1: studies on the amount of alkylketene dimer required for sizing different pulps", Nord Pulp Pap Res J vol. 1(1), pp. 26-33, 1986.

[13] T.S. Lindstrom, H. O'Brian, “On the mechanism of sizing with “ alkylketene dimers. part 2: the kinetics of reaction between alkylketene dimers and cellulose - studies on the amount of alkylketene dimer required for sizing differnt pulps", Nord Pulp Pap Res J 1(1):34-42, 1986.

[14] J.W. Davis, W.H. Robertson, and C.A. Weisgerger, A new sizing agent for paper - Alkyl Ketene Dimers. Tappi Press, 1956.

[15] F.H.J. Wenzl, The Chemical Technology of Wood. Academy Press, New York, 1970. 